\title{
Media Pembelajaran Jaringan Komputer Berbasis Android
}

\author{
Herman Saputra ${ }^{1}$,Nofriadi ${ }^{2}$, Edi Kurniawan ${ }^{3}$ \\ Sekolah Tinggi Manajemen Informatika dan Komputer Royal \\ Jln. Pof. H.M. Yamin, SH No 173. Telp 0623-42366 Kisaran \\ hermansaputra@royal.ac.id ${ }^{1}$, nofriadi@royal.ac.id ${ }^{2}$, edikurnaiwan@royal.ac.id ${ }^{3}$
}

\begin{abstract}
With the development of information technology especially smartphone technology, Android based this time, learning media capable of being deployed to help students study computer network science. Difficulties of students in the process of remembering and understand the functions of the computer network components. is research coupled with software design methods. The results achieved are the availability of applications supporting teaching and learning activities which can be obtained without being bound by time and place. Computer network science which had seemed difficult learned will feel easy and fun to be learned through an Android smartphone.
\end{abstract}

Keywords: Computer Network, Android, Smartphone

\begin{abstract}
Abstrak: Dengan memanfaatkan kecanggihan teknologi komunikasi yang telah memasuki era smartphone yang berbasis android, media pembelajaran mampu dikerahkan untuk membantu mahasiswa mempelajari ilmu jaringan komputer. Sulitnya mahasiswa dalam proses mengingat dan memahami fungsi dari komponen jaringan komputer tersebut. Metode yang digunakan dalam penelitian ini adalah penelitian ditambah dengan metode perancangan perangkat lunak. Hasil yang dicapai adalah ketersediaan aplikasi pendukung kegiatan belajar mengajar yang dapat diperoleh tanpa terikat waktu dan tempat. Ilmu jaringan komputer yang tadinya terlihat susah dipelajari akan terasa mudah dan menyenangkan untuk dipelajari melalui smartphone android.
\end{abstract}

Kata kunci: Jaringan Komputer, Android, Smartphone.

\section{PENDAHULUAN}

Kemajuan dibidang teknologi informasi dan komunikasi sudah sedemikian pesat dan telah mendorong terciptanya inovasi disegala bidang. Salah satu produk dari perkembangan teknologi sekarang ini adalah handphone. Saat ini teknologi smartphone telah berkembang pesat dengan berbagai sistem operasi seperti windows, os, ios, android, blackberry, khususnya android yang tingkat pesenan peminatnya sangat berkembang pesat. Jaringan komputer diperlukan dalam mewujudkan kemudahan kerja sama antar pengguna komputer. Jaringan komputer adalah merupakan gabungan antara teknologi komputer dan teknologi komunikasi. STMIK Royal Kisaran adalah salah satu lembaga yang bergerak dalam bidang pendidikan yang mengarah pada bidang teknologi informasi. pembelajaran jaringan komputer yang telah dilakukan sebelumnya, ditemukan bahwa tingkat penguasaan materi, khususnya pada materi konsep pengenalan komponen jaringan komputer tersebut cukup rendah.

Hasil pembelajaran jaringan komputer yang cukup rendah ini, dikarenakan dari beberapa kendala yang dihadapi selama proses pembelajaran berlangsung, diantaranya masalah yang sering dijumpai adalah siswa-siswa sering lupa pada masing-masing fungsi dari komponen jaringan komputer yang sudah dijelaskan, siswa kesulitan memahami proses pembelajaran dengan model konvensional, siswa belum memahami tentang sistem 
perkabelan misalnya kabel cross dan kabel straight untuk membangun Local Area Network (LAN).

\section{METODE PENELITIAN}

Metode yang digunakan dalam penelitian ini adalah metode deskriptif yaitu metode yang membahas masalah dengan memaparkan, menafsirkan dan menulis suatu keadaan atau peristiwa kemudian dianalisis serta mengambil kesimpulan umum dari permasalahan yang dibahas, atau suatu bentuk penelitian yang bertujuan untuk menggambarkan dan melukiskan mengenai fakta-fakta atau keadaan yang terdapat di lapangan

\section{HASIL DAN PEMBAHASAN}

\subsection{Aliran Sistem Yang di Rancang}

Adapun perancangan sitem yang dibuat pada sistem yang sedang berjalan ini sebagai berikut:

1. Dosen menyerahkan silabus mata kuliah kepada Program Studi,

2. Silabus yang sudah di tanda tangani di serahkan staff prodi.

3. Staff prodi mengelola silabus tersebut untuk bahan perkuliahan

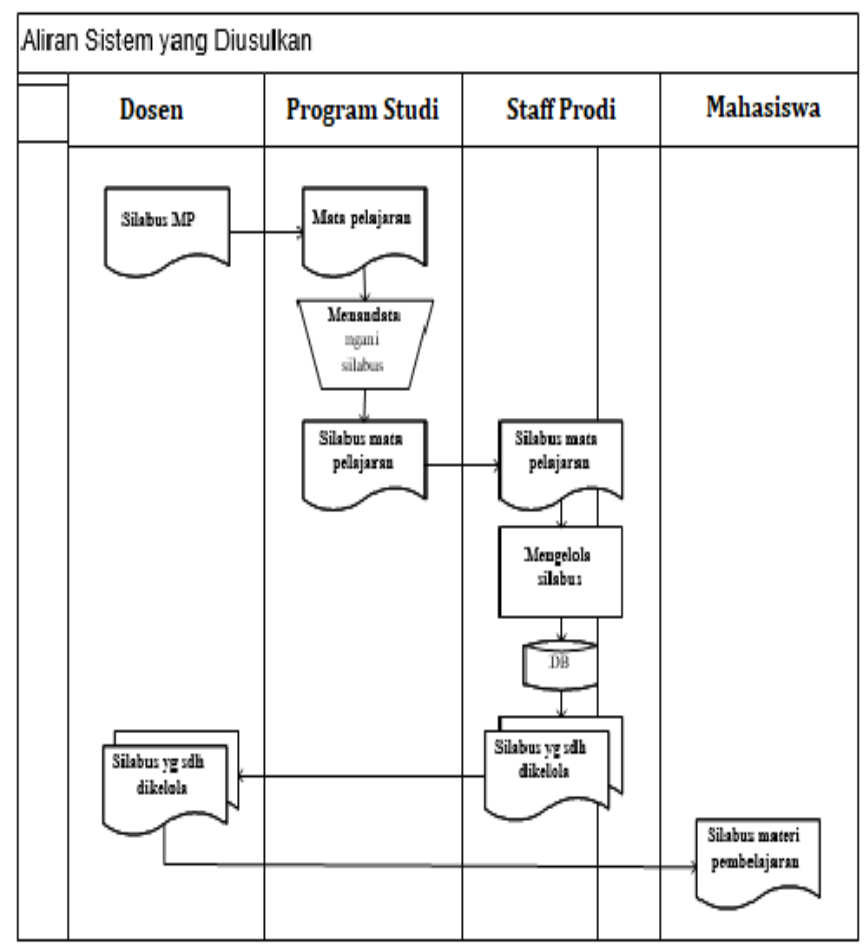

Gambar 1. Aliran Sistem yang di rancang

\subsection{Use Case}




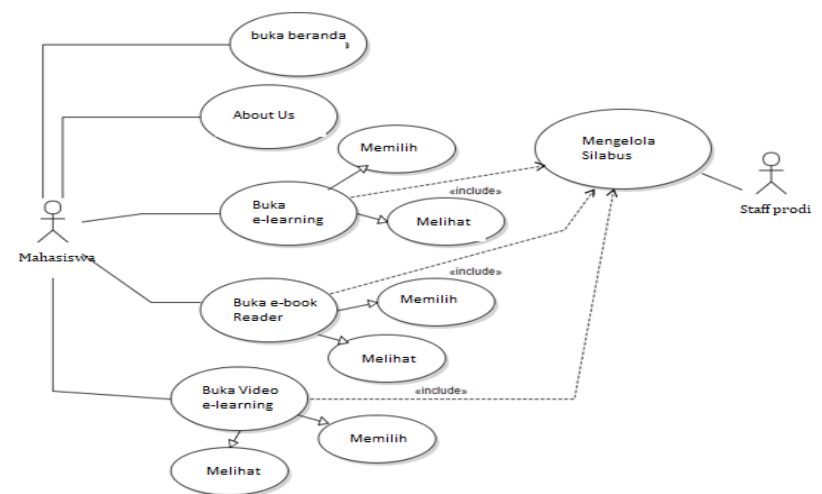

Gambar 2. Use Case

\subsection{Class Diagram}

Berikut ini adalah class diagram dari media pembelajaran jaringan komputer berbasis android

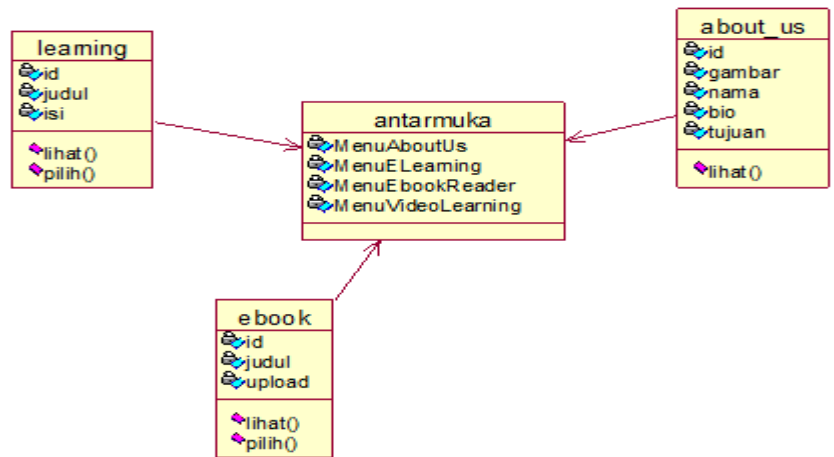

Gambar 3. Class Diagram

\subsection{Perancangan Antar Muka (User Interface)}

Interface merupakan media untuk berinteraksi antara sistem dengan penggunanya. Media penghubung tersebut adalah sebuah antar muka (interface) yang berisi struktur menu, dan panel-panel input yang berfungsi sebagai tempat memasukan data serta panelpanel output sebagai tempat untuk menampilkan data yang telah diproses. Berikut adalah interface dari media pembelajaran jaringan komputer berbasis android:

a. Tampilan Menu Utama

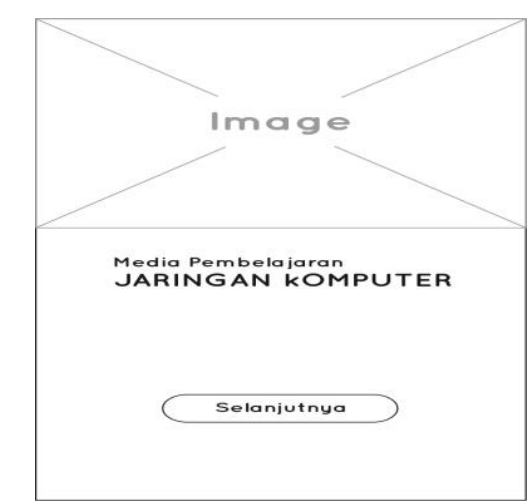

Gambar 4. Tampilan Menu Utama

b. Tampilan Menu E-Learning 


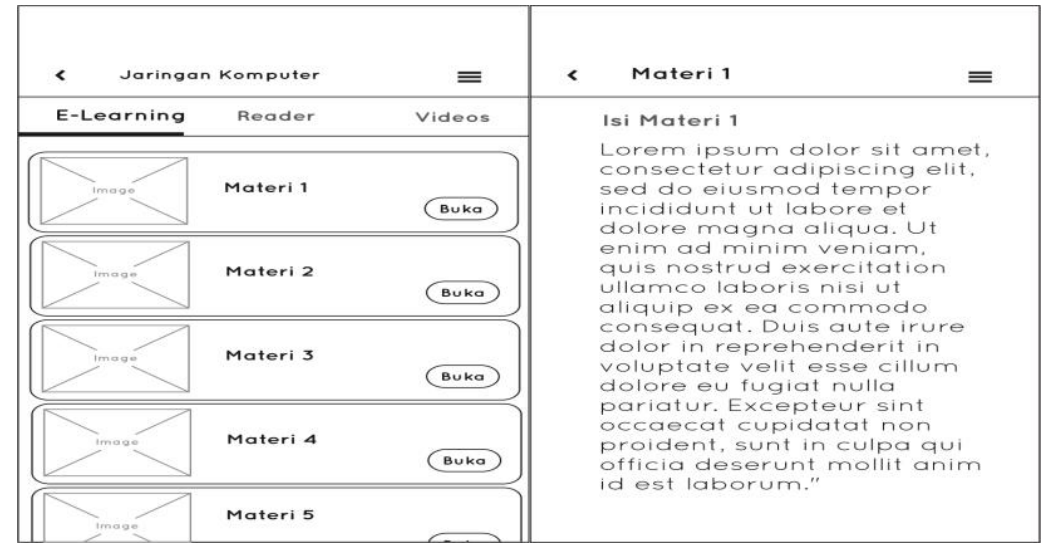

Gambar 5. Tampilan Menu E-Learning

c. Tampilan Menu E-book Jaringan

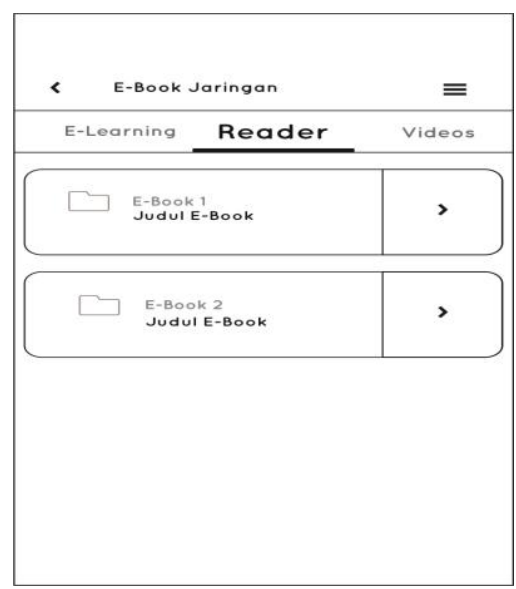

Gambar 6. Tampilan Menu E-book Jaringan

d. Tampilan Menu Video Learning

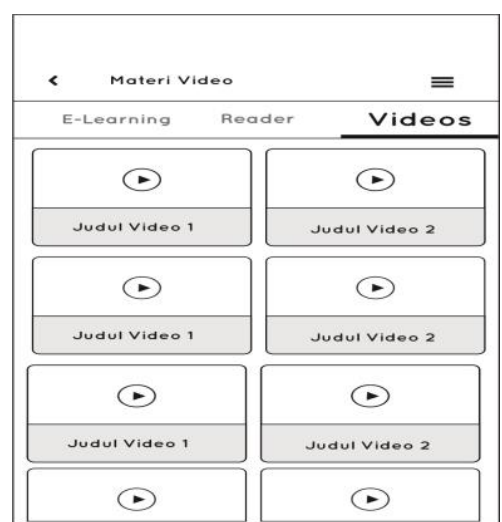

Gambar 7. Tampilan Menu Video Learning

\subsection{Tampilan Menu Utama}

Halaman ini merupakan halaman yang pertama kali tampil dalam sistem pembelajaran jaringan komputer. 


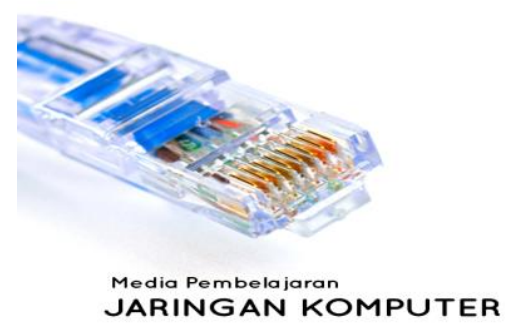

Selanjutnya

Gambar 8. Tampilan Menu Utama

\subsection{Menu E-learning}

Halaman ini merupakan halaman yang berisikan berbagai jenis jaringan computer.

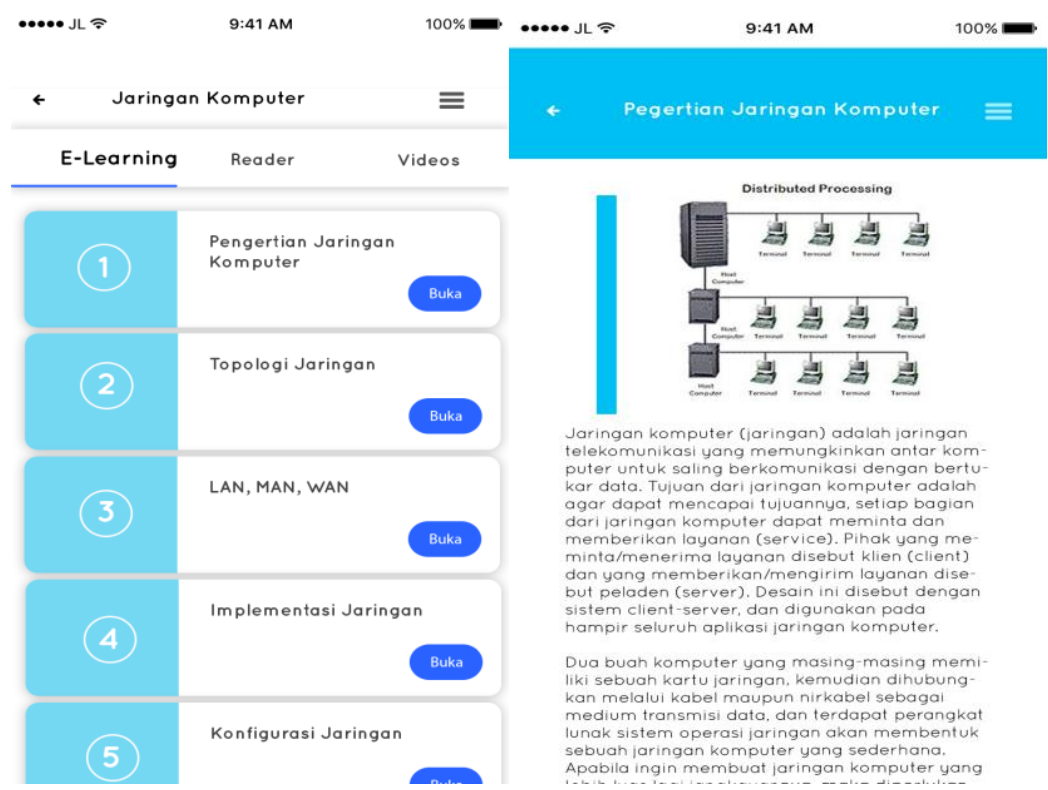

Gambar 9. Tampian Menu E-Learning

\subsection{Menu Ebook}

Halaman ini merupakan halaman yang berisikan berbagai jenis e-book tentang jaringan komputer 


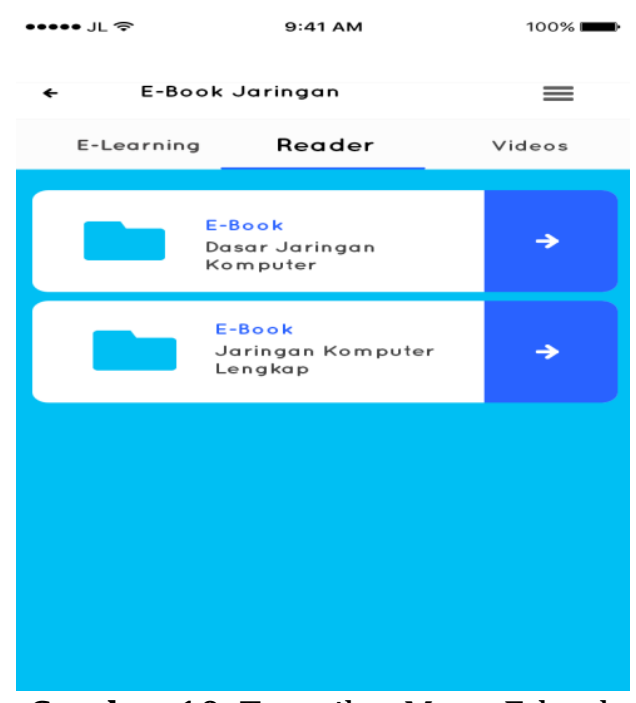

Gambar 10. Tampilan Menu E-book

a. Menu Video Learning

Halaman ini merupakan halaman yang berisikan bentuk visual dari jaringan komputer.

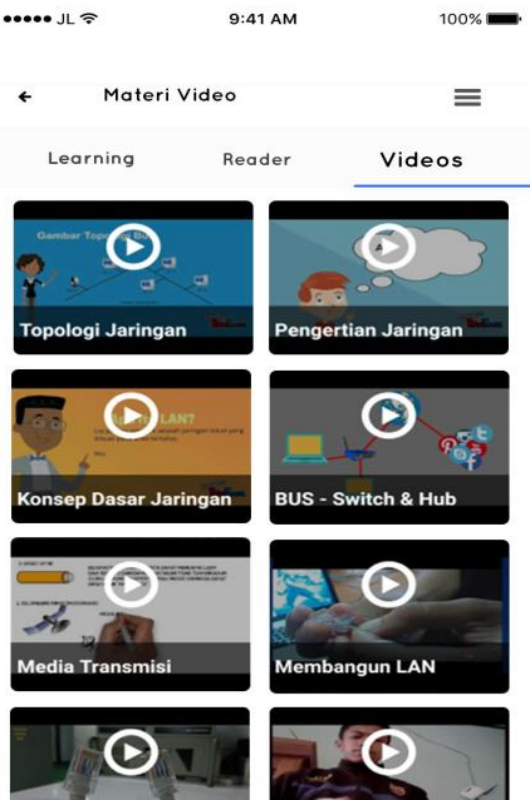

Gambar 11. Menu Video Learning

\section{KESIMPULAN}

Dari hasil analisis dan implementasi yang telah dilakukan terhadap media pembelajaran jaringan komputer berbasis android, maka dapat disimpulkan:

a. Dengan manfaat media teknologi android dapat mempermudah proses belajar mengajar tentang jaringan komputer

b. Fitur-fitur di dalam aplikasi ini dapat berjalan sesuai dengan kebutuhan pengguna yaitu terdapat materi seputar jaringan komputer serta terdapat menu e-book yang dapat di download oleh pengguna. 


\section{Saran}

Berikut ini adalah saran dari penulis:

a. Pengembangan selanjutnya perangkat lunak dapat menampilkan tutorial cara membangun setiap jaringan komputer.

b. Masih banyak informasi atau materi seputar jaringan komputer yang belum ada di aplikasi ini, untuk itu dapat dikembangkan selanjutnya untuk menambah ensiklopedia seputar jaringan Local Area Network (LAN) maupun jaringan Metropolitan Area Network (MAN) dan Wide Area Network (WAN).

\section{DAFTAR PUSTAKA}

[1] A. S, Rosa, M. Shaluhuddin. 2015. Rekayasa Perangkat Lunak Terstruktur dan Berorientasi Objek. Bandung: Informatika Bandung.

[2] Asti Herliana., Prima Muhamad Rasyid. (2016). Sistem Informasi Monitoring Pengembangan Software Pada Tahap Development Berbasis Web. Jurnal Informatika. 3:4150.

[3] Basuki Rachmadi., Triono., Faizah Hanni. (2017). Sistem Informasi Nilai Mata Pelajaran Dengan Metodologi Berbasis Objek. Jurnal Sisfotek Global. 7:96-100.

[4] Fanny Andalia., Eko Budi Setiawan. (2015). Pengembangan Sistem Informasi Pengolahan Data Pencari Kerja Pada Dinas Sosial Dan Tenaga Kerja Kota Padang. Jurnal Ilmiah Komputer dan Informatika (KOMPUTA). 4:93-98.

[5] Fathansyah. 2015. BASIS DATA Revisi Kedua. Bandung: Informatika Bandung.

[6] Franky Boy. (2014). Rekayasa Perangkat Lunak Pembelajaran Interatif Konfigurasi Jaringan Lan Mata Kuliah Jaringan Komputer Pada Universitas Dian Nuswantoro. 1-9.

[7] Lasminiasih., Sandhi P., Ali Akbar., Miftah Andriansyah., Rooswhan B. Utomo. (2016). Perancangan Sistem Informasi Kredit Mikro Mahasiswa Berbasis Web. Jurnal Sistem Informasi (JSI). 8:883-893.

[8] Napoleon Lukman. (2016). Studi Implementasi Aplikasi Manajemen Ruang Kelas "Netop School" Berbasiskan Local Area Network (LAN). Studi Implementasi Aplikasi Manajemen Ruang kelas. 11:1-14. 